\title{
Impaired modulation of pain in patients with postherpetic neuralgia
}

\author{
Gisèle Pickering $M D^{1,2,3}$, Bruno Pereira $\mathrm{PhD}^{1}$, Elodie Dufour $\mathrm{MSc}^{1}$, Sylvie Soule MSc${ }^{1}$, Claude Dubray $\mathrm{MD}^{1,2,3}$
}

G Pickering, B Pereira, E Dufour, S Soule, C Dubray. Impaired modulation of pain in patients with postherpetic neuralgia. Pain Res Manag 2014;19(1):e19-e23.

BACKGROUND: The efficiency of inhibitory pain descending pathways (evaluated using conditioned pain modulation [CPM]) has not been studied in postherpetic neuralgia (PHN).

OBJECTIVE: To compare CPM in PHN patients with healthy controls. METHODS: Nine PHN patients and nine control individuals were matched according to age and sex. Amplitudes of cortical thermal-evoked potentials were recorded on the surface of the scalp; clinical pain and thermal pain were evaluated on a 0 to 10 numerical rating scale, at baseline and at intervals during the $6 \mathrm{~min}$ after CPM (elicited by a cold pressor test, $8^{\circ} \mathrm{C}$ ). A battery of cognitive tests was performed. Amplitude differences, percentages and related areas under the curve $\left(\mathrm{AUC}_{\mathrm{CPM}}\right)$ were calculated and all data were compared between both groups; $\mathrm{P}<0.05$ was considered to be statistically significant. RESULTS: $\mathrm{AUC}_{\mathrm{CPM} 0-6 \text { min }}$ was significantly lower in PHN patients compared with controls $(-39 \pm 51 \mu \mathrm{V} / \mathrm{min}$ versus $-144 \pm 66 \mu \mathrm{V} / \mathrm{min} ; \mathrm{P}=0.0012)$ and correlated $(\mathrm{P}=0.04)$ with clinical pain intensity. Pain ratings before CPM were similar in both groups but were significantly lower in the control group 3 min after the cold pressor test. Cognitive test results were not significantly different.

CONCLUSION: Psychophysical and electrophysiological approaches have shown that patients with PHN exhibit a deficiency of pain inhibition modulation, which could signal a predisposing factor to developing chronic pain. This deficiency was not linked to the cognitive performance but rather to subtle in situ cognitivoemotional adaptations, which remain to be investigated.

Key Words: CPM; DNIC; Neuropathic pain; Shingles

A bnormal pain modulation has been described in various disease states such as fibromyalgia (1-3), irritable bowel syndrome (4-7), temporomandibular disorders $(4,8-10)$ or tension-type headache (11). Pain modulation has, however, been little explored in neuropathic pain conditions (12-16) and published reports have not specifically studied postherpetic neuralgia (PHN). $\mathrm{PHN}$ is a neuropathic type of pain that appears in the dermatomes affected by the reactivation of the herpes zoster virus in the dorsal root ganglion. PHN develops in $10 \%$ to $28 \%$ of patients with herpes zoster virus, especially in older individuals $(17,18)$, and presents with characteristics of neuropathic pain including variable degrees of allodynia and hyperalgesia. PHN is associated with a considerable amount of persistent pain and greatly impacts functional status and quality of life $(19,20)$. The reasons why shingles develops into PHN in some patients are still undetermined, but the intensity of acute shingles pain, the large area of rash and age may be predicting factors of the severity of PHN, while the early use of antiviral (21) and analgesic drugs (22) may reduce the incidence of PHN; however, studies have shown contradictory results (23). Apart from these factors, in light of the abnormal modulation of pain shown already in idiopathic pain syndromes and in the specific condition of chemotherapy-induced neuropathy (16), we hypothesized that PHN patients could also have an abnormal activity within diffuse noxious inhibitory controls (DNIC). Such a dysfunction could explain interindividual variability in pain severity and in developing PHN and, conversely, chronic pain could

\section{L'altération de la modulation de la douleur chez des patients ayant une névralgie postherpétique}

HISTORIQUE : L'efficacité des voies descendantes inhibitrices de la douleur (évaluée par la modulation conditionnée de la douleur [MCD]) n'a pas été étudiée dans les cas de névralgie postherpétique (NPH).

OBJECTIF : Comparer la MCD chez les patients souffrant de NPH à des sujets témoins en santé.

MÉTHODOLOGIE : Neuf patients ayant une NPH et neuf sujets témoins ont été appariés selon l'âge et le sexe. Les chercheurs ont consigné l'amplitude de leurs potentiels évoqués corticaux par les stimulations thermiques à la surface du cuir chevelu et évalué leur douleur clinique et thermique sur une échelle numérique de 0 à 10 en début d'étude et à divers intervalles pendant les six minutes suivant la MCD (causée par un test au froid à $8^{\circ} \mathrm{C}$ ). Ils ont effectué une batterie de tests cognitifs. Ils ont calculé les différences et les pourcentages d'amplitude ainsi que les aires sous la courbe connexes $\left(\mathrm{ASC}_{\mathrm{MCD}}\right)$ et comparé toutes les données entre les deux groupes. Un $\mathrm{P}<0,05$ était considéré comme statistiquement significatif. RÉSULTATS : L'ASC ${ }_{M C D 0-6 m i n}$ était significativement plus faible chez les patients ayant une NPH que chez les sujets témoins $(-39 \pm 51 \mu \mathrm{V} / \mathrm{min}$ par rapport à $-144 \pm 66 \mu \mathrm{V} / \mathrm{min} ; \mathrm{P}=0,0012)$ et corrélée avec l'intensité de la douleur clinique $(P=0,04)$. L'évaluation de la douleur avant la MCD était similaire dans les deux groupes, mais significativement plus faible dans le groupe témoin trois minutes après le test au froid. Les résultats des tests cognitifs n'étaient pas différents sur le plan statistique.

CONCLUSION : Les approches psychophysiques et électrophysiologiques ont démontré que les patients ayant une NPH présentent une carence de modulation de l'inhibition de la douleur, qui pourrait signaler un facteur prédisposant aux douleurs chroniques. Cette carence n'était pas liée à la performance cognitive, mais à de subtiles adaptations cognitivo-affectives in situ qui n'ont pas encore été explorées.

also generate a diminution of conditioned pain modulation (CPM) functionality, resulting in a vicious cycle. Descending pain pathways originate in brainstem nuclei, the hypothalamus and the cortex, and interact with afferent fibres, interneurons and projecting neurons in the dorsal horn of the spinal cord. It is possible to stimulate these descending inhibitory pathways in human experimental pain studies by submitting a subject to an intense painful stimulus such as a painful cold sensation (the cold pressor test). According to recent expert recommendations (24), this inhibitory phenomenon, the DNIC-like effect $(25,26)$, also known as CPM, has been studied with a psychophysical and/or objective electrophysiological approach in a number of publications (5,27-30). CPM is also influenced by higher-order cognitive and affective activity $(27,29,31)$, which contribute to abnormal pain regulation.

The aims of the present study were to assess pain and CPM efficiency in patients with PHN compared with healthy controls. Furthermore, considering that induced analgesia may also be influenced by higher-order cognitive processes, the present study also aimed to assess whether cognitive status correlates with CPM in patients with PHN.

Study

METHODS

The present prospective, controlled study was performed in the Clinical Pharmacology Centre, University Hospital of ClermontFerrand, France. The study was approved by the Ethics Committee,

${ }^{1}$ Centre Hospitalier Universitaire de Clermont-Ferrand, Centre de Pharmacologie Clinique; ${ }^{2}$ Inserm, CIC 501, UMR 766; ${ }^{3}$ Clermont Université, Laboratoire de Pharmacologie, Faculté de médecine, Clermont-Ferrand, France

Correspondence: Dr Gisèle Pickering, Clinical Pharmacology Centre, Bâtiment 3C, CHU, Hopital G Montpied, 63001 Clermont-Ferrand cedex, France. Telephone 33-0-4-73-17-84-16, fax 33-0-4-73-17-84-12, e-mail gisele.pickering@udamail.fr 
was declared on clinicaltrials.gov (NCT01053845) and followed standardized ethical and safety Good Clinical Practice Guidelines.

\section{Participants}

Patients were recruited from the pain clinic and were included after signing an informed consent form, and if they fulfilled the International Association for the Study of Pain criteria for PHN, with a history of shingles followed by persistent pain with a pain intensity of $\geq 4$ of 10 on a numerical rating scale (NRS). Patients were instructed to continue using their medications before the beginning of the study, but to stop taking them from 19:00 the day before the tests; usual treatment was resumed immediately after completion of the tests. Patients with any change in drug treatment over the previous two months and neuropathic pain duration $>5$ years or $<6$ months were excluded. Healthy volunteers were not allowed any medication for one month before the test and exclusion criteria for both groups included any impairment of eyesight or colour vision (for cognitive tests). For each PHN patient, a healthy volunteer matched for age and sex was concomitantly included.

\section{Study design}

Participants were comfortably installed in a quiet room after a standard clinical examination and were asked to rate their mean clinical pain over the past week on an NRS that ranged from 0 (absolutely no pain) to 10 (worst pain imaginable). The first test consisted of recording cortical evoked potentials during application of a thermode on the dominant forearm and was followed by a cold pressor test (CPT) on the controlateral arm. Stimuli were applied on a nonpainful area because all patients were experiencing thoracolumbar neuropathic pain. From the end of the $\mathrm{CPT}$, cortical evoked potentials were recorded at baseline ( $\mathrm{t} 0)$ and up to $6 \mathrm{~min}(1 \mathrm{~min}, 2 \mathrm{~min}, 3 \mathrm{~min}$ and $6 \mathrm{~min}$ after the end of CPT, labelled $\mathrm{t} 1$, t2, t3 and t6) to evaluate the impact of the CPT on the descending pathways. Thermal pain intensity was recorded using the NRS. The study hypothesis postulated that a lesser modulation of pain and a diminished CPM response would be observed in PHN patients.

\section{Cortical evoked potentials}

Cortical pain waveforms were recorded using pain evoked potentials (contact heat evoked potential stimulator [CHEPS], Medoc Ltd, Israel); the amplitude of the signal (N2P2 wave) was the main evaluation criteria. The CHEPS rapidly stimulates cutaneous small nerve fibres (32), and resulting evoked potentials can be recorded from the scalp. It was connected to Viking Select (Viasys Healthcare, USA). The procedure was adapted from that described by Granovsky et al (33) and is commonly used for experimental pain studies. The applied stimulation methodology is widely used for selective stimulation of small mylenated fibers inducing A-delta evoked potential. The thermode was applied on the volar side of the dominant forearm and the thermode temperature increased from $35.0^{\circ} \mathrm{C}$ to $51.0^{\circ} \mathrm{C}$; this stimulus generates a very rapid pin-prick sensation. The thermofoil permitted a heating rate of up to $70.0^{\circ} \mathrm{C} / \mathrm{s}$ and the Peltier device allowed a cooling rate of $40.0^{\circ} \mathrm{C} / \mathrm{s}$. The baseline temperature was $35.0^{\circ} \mathrm{C}$ and the peak temperature was reached in $<200 \mathrm{~ms}$. Each stimulus block consisted of six constant-intensity stimuli applied to the same site at pseudorandom interstimulus intervals of approximately $15 \mathrm{~s}$. The thermode remained at the same site during each block. This adaptation of a published protocol (31) may be a limitation to the present study; however, in a number of pilot studies performed by the team, sensitization of the skin and/or a blunting of pain integration after 25 stimuli was observed even when moving the thermode between stimuli. The first stimulus was discarded from the analysis because of possible expectation, surprise or novelty effects on the participant. The mean was calculated on the five following stimuli. CHEPS were recorded from six midline electrodes and data recorded from the $\mathrm{Cz}$ (vertex) position were analyzed. Linked earlobe electrodes served as reference and the impedance from all electrodes was $<5 \mathrm{kU}$. Arm stimulations evoked well-defined potentials in all participants. The average amplitude values of both negative and positive components of the wave forms were recorded and the peak-to-peak N2P2 amplitude (in $\mu \mathrm{V})$ was taken as the main evaluation criterion of pain integration at central level (32).

\section{CPT}

The CPT consisted of immersion in a bath of circulating water maintained at $8^{\circ} \mathrm{C}$. The standardized instructions for the procedure directed participants to keep their hand in the water for $120 \mathrm{~s}$, but explained that if the sensation became intolerable, participants could remove their hand at any time. After completion, participants immersed their hand in a warmer bath for $1 \mathrm{~min}$ and were then given a heated towel to warm and dry their hand. Previous research (34), including the authors' (35), have shown that the CPM effect (evaluated by pain thresholds or pain intensity changes) fades gradually after cessation of the conditioning stimulus and that it returns to baseline values within approximately $5 \mathrm{~min}$ to $8 \mathrm{~min}$ after stimulation (36). Using thermal evoked potentials in young healthy volunteers, the authors have shown in healthy volunteers (unpublished data) that the amplitude of the N2P2 wave diminishes during the $\mathrm{CPT}$ at $8^{\circ} \mathrm{C}$ and that reversal of $\mathrm{CPM}$ is completed 6 min after the end of the CPT.

Pain N2P2 amplitude and pain intensity by NRS were then assessed $1 \mathrm{~min}, 2 \mathrm{~min}, 3 \mathrm{~min}$ and $6 \mathrm{~min}$ after the end of CPT. After completion of the tests, participants were allowed to rest, were provided with a snack and cognitive tests were then performed.

\section{Cognitive tests}

A program of tests was set up on the Cambridge Neuropsychological Test Automated Battery (Cantab, United Kingdom) and included reaction time, semantic memory, decision-making and spatial memory. The subject taking these tests interacts with the computer system via a touch screen under the supervision of a clinical research assistant.

Choice Reaction Time (RTI) is an attention test that measures speed of response and movement in a five-choice paradigm. The outcome measure is the five-choice reaction time (RTI; in ms), ie, the speed with which the subject releases the press pad button in response to a stimulus in any one of five locations. Semantic memory was explored using the Graded Naming Test (GNT), which provides a measure of semantic memory by assessing object naming ability. The test consists of naming a number of drawings with increasing difficulty levels. The GNT per cent correct outcome measure reports the percentage of objects correctly identified by the subject. Decision making with the Information Sampling Task (IST) tests impulsivity and decision making. IST is a task designed to measure predecisional processing, in which the subject gathers and evaluates information before making a decision. Inadequate reflexion means that decision will be made on the basis of less evidence and, therefore, will reduce the accuracy of the eventual decision. The subject is instructed that he/she is playing a game for points, which he/she can win by making a correct decision about which colour is mainly displayed under the grey boxes on the screen. The outcome measure chosen is the number of discrimination errors, ie, the number of trials in which the subject chose a colour and made a decision that was not logically based on evidence available to the subject at the time. Spatial working memory and spatial learning were evaluated using the Stockings of Cambridge (SOC) test, a test of spatial planning and working memory. The subject is shown two displays containing coloured balls and must use the balls in the lower display to copy the pattern shown in the upper display. The chosen outcome measure for the SOC test is the mean initial thinking time (ms) and gives an indication of the time taken to plan the problem solution.

\section{Statistical analysis}

The number of patients was calculated from previous data obtained in the authors' laboratory involving thermal evoked potentials, with a mean $( \pm$ SD) $\mathrm{N} 2 \mathrm{P} 2$ amplitude of $22.33 \mu \mathrm{V} \pm 7.51 \mu \mathrm{V}$, an expected variation of $15 \mu \mathrm{V}$, an alpha risk of $5 \%$ and beta risk of $5 \%$, giving a power of $95 \%$. Data analysis was performed using SPSS (IBM Corporation, USA). The amplitude $(\mathrm{A} ; \mu \mathrm{V})$ of the evoked potential and the pain intensity (NRS) were recorded at each timepoint. The N2P2 amplitude difference $(\mathrm{Ad} ; \mu \mathrm{V})$ between each time point $(\mathrm{t} 1, \mathrm{t} 2, \mathrm{t} 3$ and $\mathrm{t} 6)$ 


\begin{tabular}{|c|c|c|c|}
\hline & Control & PHN & $\mathbf{P}$ \\
\hline Clinical pain NRS & & $5.7 \pm 1.3$ & \\
\hline \multicolumn{4}{|l|}{ Thermal stimulus NRS } \\
\hline to & $3.7 \pm 0.5$ & $4.4 \pm 1.6$ & 0.18 \\
\hline $\mathrm{t} 1$ & $3.4 \pm 0.7$ & $4.4 \pm 2.0$ & 0.36 \\
\hline t2 & $3.0 \pm 0.5$ & $4.2 \pm 1.3$ & 0.39 \\
\hline $\mathrm{t} 3$ & $2.0 \pm 0.8$ & $4.0 \pm 0.8$ & 0.03 \\
\hline t6 & $3.1 \pm 1.1$ & $4.0 \pm 1.0$ & 0.33 \\
\hline End of CPT NRS & $6.7 \pm 1.9$ & $6.0 \pm 2.3$ & 0.51 \\
\hline Latency withdrawal, $\min$ & $1: 48 \pm 0: 26$ & $1: 48 \pm 0: 38$ & 1.00 \\
\hline
\end{tabular}

Data presented as mean $\pm S D$ unless otherwise indicated. PHN Postherpetic neuralgia; to, t1, t2, t3 and t6 Time $0 \mathrm{~min}, 1 \mathrm{~min}, 2 \mathrm{~min}, 3 \mathrm{~min}$ and $6 \mathrm{~min}$ after end of $C P T$

and baseline (t0), the percentage of amplitude difference ( $\%$ amplitude difference $=\mathrm{Ad} \times 100 / \mathrm{AtO})$ were calculated and the area under the curve $\left(\mathrm{AUC}_{\mathrm{CPM}}\right)$ of $\mathrm{Ad}$ was calculated for each group for the entire period of the experiment from to to t6 $(0 \mathrm{~min}$ to $6 \mathrm{~min})$. Statistical differences between PHN patients and healthy control individuals were established using a repeated-measures ANOVA followed by a Tukey-Kramer post hoc (multiple comparisons) test. These analyses were completed using mixed models taking into account between- and within-subject variability (random effect); the interactions time $\times$ group (PHN patients or healthy controls) were studied and presented when appropriate. Residual normality was checked for these models. Concerning intragroup comparisons, usual paired tests (paired $t$ test or Wilcoxon test) were used considering a type I error inflation (Bonferroni correction). All results were expressed as mean \pm SD. The correlation between clinical pain obtained by NRS before the experiment and the AUC was analysed using Pearson correlation coefficient and linear regression. The tests were two-sided, with a type I error set at $\alpha=0.05$.

\section{RESULTS}

Nine healthy volunteers and nine patients with peripheral PHN (thoracolumbar distribution; none had ophthalmic or upper limb PHN) were recruited from the pain clinic. Data from these 18 participants (mean age $67 \pm 4$ years), nine with PHN (mean age $67 \pm 4$ years) and nine healthy volunteers (mean age $65 \pm 5$ years), matched according to age (no significant difference) and sex (10 women; no significant difference), were analyzed. All patients reported a history of shingles followed by persistent pain with neuropathic characteristics (mean NRS 5.7 \pm 1.3 ; Douleur Neuropathique 4 questionnaire score $8 \pm 1$ ) and allodynia (stroking of the skin evoked a painful sensation) for a mean of $47 \pm 8$ months.

A number of parameters (Table 1), including baseline thermal pain NRS score, end-of-immersion thermal pain intensity with the thermode at $51^{\circ} \mathrm{C}$ and latency before withdrawal of the hand in the CPT, were not significantly different between PHN patients and controls.

At $\mathrm{t} 3$, thermal pain intensity $(2.0 \pm 0.8)$ for healthy control subjects differed significantly from that at baseline $(3.7 \pm 0.5)(\mathrm{P}<0.05)$. For PHN patients, pain intensity at $\mathrm{t} 1, \mathrm{t} 2, \mathrm{t} 3$ and $\mathrm{t} 6$ did not differ significantly from those at baseline. These results were confirmed by intergroup analysis using random-effects models. The interaction at $\mathrm{t} 3$ was significant $(z=3.69 ; \mathrm{P}<0.001)$.

When considering the evoked potentials waveforms, if CPM is functional, CPT would be expected to induce a decrease of N2P2 amplitude and a return to baseline value at $6 \mathrm{~min}$. Amplitude differences $(\mu \mathrm{V})$ and per cent of amplitude differences (Table 2, Figure 1, Figure 2) between baseline and each point in time were smaller for PHN patients than for healthy subjects. There was a correlation between clinical pain intensity (the week before the test) and
TABLE 2

Electrophysiological data showing amplitude and latency of evoked potentials waves

\begin{tabular}{cccc}
\hline & Control & PHN & P \\
\hline Amplitude, $\mu \mathrm{V}$ & & & \\
t0 & $27.3 \pm 6.8$ & $25.5 \pm 8.8$ & 0.63 \\
t1 & $16.8 \pm 8.5$ & $20.8 \pm 8.7$ & 0.02 \\
t2 & $15.6 \pm 6.4$ & $23.0 \pm 5.0$ & $<0.001$ \\
t3 & $13.7 \pm 7.5$ & $22.5 \pm 9.2$ & $<0.001$ \\
t6 & $26.8 \pm 5.9$ & $26.4 \pm 9.1$ & 0.58 \\
Amplitude difference, $\mu \mathrm{V}$ & & & \\
t1-t0 & $-11.2 \pm 5.5$ & $-4.7 \pm 6.2$ & 0.21 \\
t2-t0 & $-11.7 \pm 4.9$ & $-2.5 \pm 5.7$ & 0.04 \\
t3-t0 & $-13.7 \pm 2.8$ & $-2.9 \pm 3.9$ & 0.03 \\
t6-t0 & $-0.5 \pm 3.1$ & $0.9 \pm 2.0$ & 0.48 \\
Amplitude difference, \% & & & \\
t1-t0 & $-41.1 \pm 20.2$ & $-18.7 \pm 25.3$ & 0.17 \\
t2-t0 & $-42.9 \pm 16.9$ & $-6.5 \pm 17.9$ & 0.005 \\
t3-t0 & $-52.2 \pm 15.7$ & $-11.7 \pm 16.8$ & 0.001 \\
t6-t0 & $-0.5 \pm 13.3$ & $3.3 \pm 8.3$ & 0.51 \\
Latency, ms & & & \\
t0 & $478.2 \pm 43.2$ & $431.8 \pm 91.4$ & 0.16 \\
t1 & $492.2 \pm 65.1$ & $449.6 \pm 101.5$ & 0.29 \\
t2 & $490.5 \pm 84.6$ & $451.1 \pm 99.9$ & 0.25 \\
t3 & $482.3 \pm 100.4$ & $461.1 \pm 98.2$ & 0.52 \\
t6 & $478.9 \pm 77.7$ & $462.0 \pm 112.9$ & 0.68 \\
\hline
\end{tabular}

Data presented as mean $\pm S D$ unless otherwise indicated. PHN Postherpetic neuralgia; $t 0, t 1, t 2, t 3$ and t 6 Time $0 \mathrm{~min}, 1 \mathrm{~min}, 2 \mathrm{~min}, 3 \mathrm{~min}$ and $6 \mathrm{~min}$ after end of cold pressor test

$\mathrm{AUC}_{\mathrm{CPM}}$ in PHN patients (Figure 3) but no correlation in either group between thermal baseline pain intensity and $\mathrm{AUC}_{\mathrm{CPM}}$.

Cognitive tests were not significantly different between PHN patients and healthy controls (RTI $510 \pm 207 \mathrm{~ms}$ versus $495 \pm 150 \mathrm{~ms}$; IST (number of errors) $10 \pm 5$ ms versus $9 \pm 5 \mathrm{~ms}$; SOC $9395 \pm 5101 \mathrm{~ms}$ versus $9130 \pm 5203 \mathrm{~ms}$; and GNT $79 \pm 9 \%$ versus $81 \pm 10 \%$, respectively). There was no correlation between any of the cognitive test results and $\mathrm{AUC}_{\mathrm{CPM}}$.

\section{DISCUSSION}

The first aim of the present study was to explore, for the first time, CPM efficiency in patients with PHN, and the results show a CPM deficit in pain inhibition in PHN patients. In these long-term neuropathic pain patients with four years of chronic pain since shingles flare, one suggestion is that ongoing chronic pain may have 'exhausted' DNIC (36), leading to a low pain inhibitory capacity and/or an enhanced facilitation in the descending pathways. This deficit in CPM efficiency has been described in various pain conditions (1-19) including Huntington's disease (37), temporal lesions (38) or Parkinson's disease (39), with different modalities using electrical, pressure or thermal stimuli, but could not be demonstrated in a number of other pathologies such as rheumatoid arthritis (40) or Parkinson's disease (41). The postulate that CPM deficiency may be specific to medically unexplained pain syndromes (36) is not supported by our finding because shingles pathophysiology is well described. Our study combined psychophysical and electrophysiological approaches, and both techniques demonstrated a significant difference between patients and controls, from 2 min after the end of CPT with the cortical recording and at 3 min with the NRS.

The present study also showed a negative correlation between clinical pain and CPM, suggesting that a less efficient CPM may be a predisposing factor to acquire neuropathic pain; this result confirms similar findings in chemotherapy-induced neuropathic pain (19) and in postsurgical pain $(42,43)$. The deficit in CPM modulation may indeed be a cause or a consequence of chronic pain with the perpetuation of a continuous vicious cycle. This cycle may, however, be broken, as was shown 


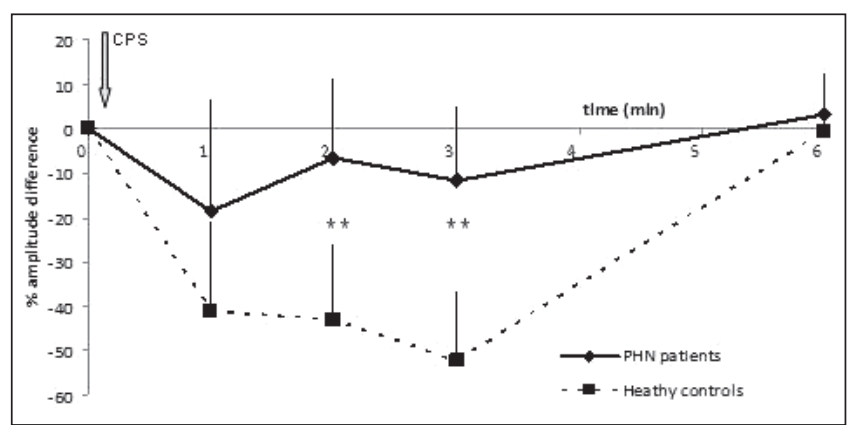

Figure 1) Percentage of N2P2 amplitude differences registered on the scalp in response to thermal stimuli applied on the dominant arm after a conditioning pain stimulus consisting in the immersion of the contralateral arm in cold water $\left(8^{\circ} \mathrm{C}\right)$ to compare conditioned pain modulation in patients with postherpetic neuralgia (PHN) with healthy controls. A significant difference between the two groups was observed $(* * P<0.01)$. These results were confirmed by intergroup analysis using random-effects models. The interactions at $2 \mathrm{~min}(\mathrm{t} 2)$ and $3 \mathrm{~min}(\mathrm{t} 3)$ after the conditioning pain stimulus were significant $(z=3.83 ; P<0.001$, and $z=4.42 ; P<0.001$, respectively)

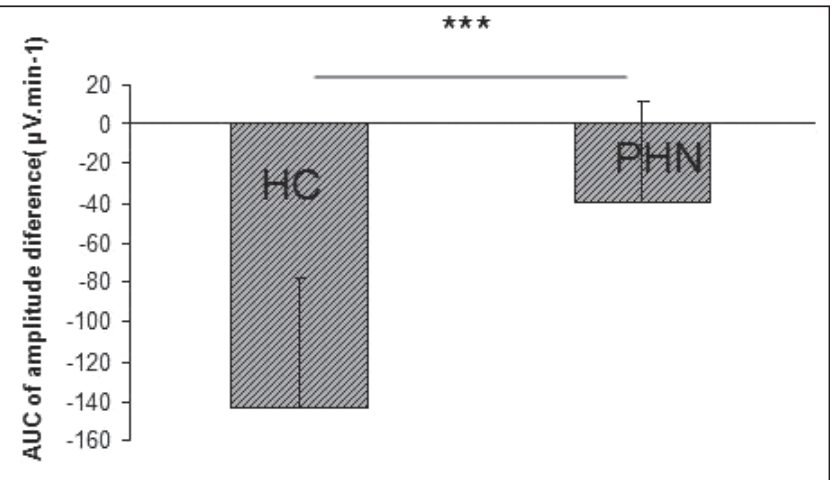

Figure 2) Comparison of the areas under the curve (AUC) of the N2P2 amplitude differences obtained in patients with postherpetic neuralgia $(\mathrm{PHN})$ and in healthy controls (HC) $(* * * P=0.0012)$

in a study involving osteoarthritis patients, in which DNIC was impaired but restored after appropriate treatment and the alleviation of pain (44). PHN in its severe form is difficult to alleviate despite polymedication and successive drug trials; however, CPM status may be a guide in PHN treatment for adequate drug prescription, as has been shown with duloxetine in cancer patients (16). Besides the CPM deficit, facilitation of pain may have also occurred (16): two PHN patients in our study had larger N2P2 waves (more integration of pain) on the 6 min CPM testing, suggesting a sensitization phenomenon from heterotopic stimuli and a widespread hyperalgesia. All PHN patients had, however, some degree of descending inhibition and it appears that, from the beginning of the CPT, facilitation phenomena may override inhibition with a large interindividual variability and a disequilibrium in favour of pain - a 'pronociceptive' phenomenon (16).

It has also been suggested (45) that poor CPM efficiency in pain patients could result from the fact that clinical pain combined with an experimental applied conditioning stimulus (cold water) may act as two concomitant applied stimuli and diminish pain inhibition. Recordings of cortical waveforms suggest that PHN and healthy controls integrate pain similarly before any conditioning stimulus, with similar N2P2 amplitudes, suggesting that A-delta functioning in a nonpainful region was not impaired, while it has been shown to be impaired in neuropathic painful regions in other publications (46). Induction of the conditioning stimulus, however, triggers different brain activation patterns in PHN and healthy controls, demonstrating a dysfunction of integration of thermal nociceptive inputs in PHN patients.

No correlation was observed between thermal pain intensity at $\mathrm{t} 0$ and CPM, suggesting that experimental pain is a poor predictor of CPM

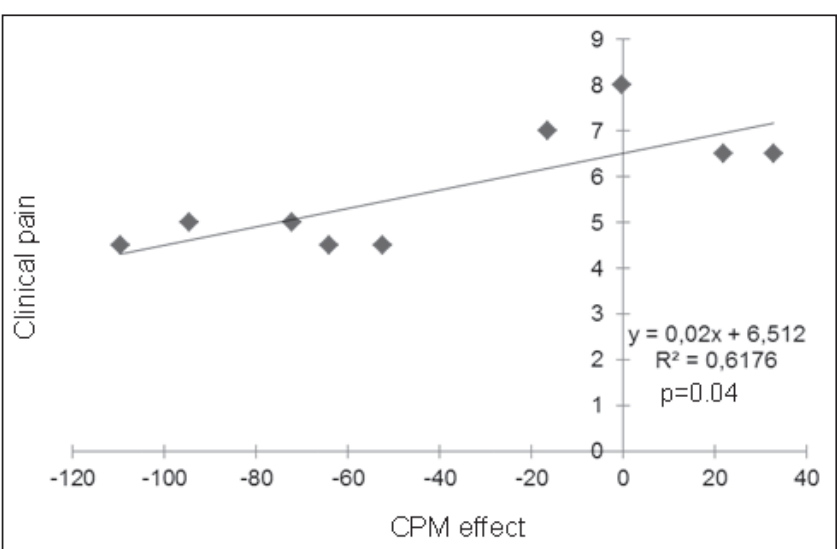

Figure 3) Correlation between clinical pain obtained by numerical rating scale before the experiment and the area under the curve. CPM Conditioned pain modulation

efficiency. The observation that baseline thermal pain thresholds are not significantly different between PHN patients and healthy control individuals suggests that clinical ongoing pain does not activate CPM mechanisms and confirms previous findings in chronic and neuropathic pain of various etiologies (46-48). The deficient CPM may also be because the stimulus is not strong enough and is always lower than ongoing pain.

It has been shown that supraspinal and higher-order cognitive and affective processes may also influence descending regulation $(27,29,31,49)$. Expectation, anticipation, fear of pain and emotional turmoil are expected to be more pronounced in PHN patients, who are also less likely to get easily distracted and are hypervigilant: these factors contribute to reducing CPM on inhibitory pathways and, hence, may increase hyperalgesia. We measured the cognitive performance with specific tests focusing on frontal lobe function in a soft environment: although slower, the cognitive performance is not significantly impaired in our PHN patients compared with controls and does not predict the degree of CPM. As measured here, the cognitive performance illustrates the cognitive traits of the patients but does not preclude the cognitive-emotional interactions that may have been at play during the painful test. Cognitive manipulation (49) during the test could bring supplemental information on the cognitive and emotional status of the patients. Emerging data also suggest that CPM deficit is influenced by sociodemographic factors, anxiety, depression and sleep quality, which remain poorly understood in PHN and require further study.

\section{CONCLUSION}

The results of the present study provide preliminary evidence, with psychophysical and electrophysiological approaches, that patients experiencing long-standing PHN present a deficiency of pain inhibition modulation. This impaired modulation of pain may be a predisposing factor to develop chronic pain and its assessment could be a guide for optimizing analgesic treatment. It is not linked to cognitive performance; however, qualitative contextual cognitivoemotional influences on descending pathways remain to be investigated.

DISCLOSURES AND ACKNOWLEDGEMENTS: The authors have no conflicts of interest to declare with regard to the research reported. The authors thank the participants of the study.

\section{REFERENCES}

1. Kosek E, Hansson P. Modulatory influence on somatosensory perception from vibration and heterotopic noxious conditioning stimulation (HNCS) in fibromyalgia patients and healthy subjects. Pain 1997;70:41-51.

2. Lautenbacher S, Rollman GB. Possible deficiencies of pain modulation in fibromyalgia. Clin J Pain 1997;13:189-96. 
3. Staud R, Robinson ME, Vierck CJ Jr, Price DD. Diffuse noxious inhibitory controls (DNIC) attenuate but not in normal females or fibromyalgia patients. Pain 2003;101:167-74.

4. King CD, Wong F, Currie T, et al. Deficiency in endogenous modulation of prolonged heat pain in patients with irritable bowel syndrome and temporomandibular disorder. Pain 2009;143:172-8.

5. Wilder-Smith CH, Schindler D, Lovblad K, Redmond SM, Nirkko A. Brain functional magnetic resonance imaging of rectal pain and activation of endogenous inhibitory mechanisms in irritable bowel syndrome patient subgroups and healthy controls. Gut 2004;53:1595-601.

6. Wilder-Smith CH, Robert-Yap J. Abnormal endogenous pain modulation and somatic and visceral hypersensitivity in female patients with irritable bowel syndrome. World J Gastroenterol 2007;13:3699-704

7. Piché M, Bouin M, Arsenault M, Poitras P, Rainville P. Decreased pain inhibition in irritable bowel syndrome depends on altered descending modulation and higher-order brain processes. Neuroscience 2011;195:166-75.

8. Maixner W, Fillingim R, Booker D, Sigurdsson A. Sensitivity of patients with painful temporomandibular disorders to experimentally evoked pain. Pain 1995;63:341-51

9. Maixner W, Fillingim R, Sigurdsson A, Kincaid S, Silva S. Sensitivity of patients with painful temporomandibular disorders to experimentally evoked pain: Evidence for altered temporal summation of pain. Pain 1998;76:71-81.

10. Bragdon EE, Light KC, Costello NL, et al. Group differences in pain modulation: Pain-free women compared to pain-free men and to women with TMD. Pain 2002;96:227-37.

11. Pielsticker A, Haag G, ZaudigM, Lautenbacher S. Impairment of pain inhibition in chronic tension-type headache. Pain 2005;118:215-23.

12. Witting N, Svensson P, Jensen TS. Differential recruitment of endogenous pain inhibitory systems in neuropathic pain patients. Pain 2003;103:75-81.

13. Bouhassira D, Danziger N, Attal N, Guirimand F. Comparison of the pain suppressive effects of clinical and experimental painful conditioning stimuli. Brain 2003;126:1068-78.

14. Tuveson B, Leffler AS, Hansson P. Heterotopic noxious conditioning stimulation (HNCS) reduced the intensity of spontaneous pain, but not of allodynia in painful peripheral neuropathy. Eur J Pain 2007;11:452-62.

15. Love-Jones SJ, Besson M, Steeds CE, et al. Homotopic stimulation can reduce the area of allodynia in patients with neuropathic pain. Eur J Pain 2009;13:942-8.

16. Nahman-Averbuch H, Yarnitsky D, Granovsky Y, et al. Pronociceptive pain modulation in patients with painful chemotherapy-induced polyneuropathy. J Pain Symptom Manage 2011;42:229-38.

17. Hope-Simpson RE. Epidemiology of shingles. J R Soc Med 1991;84:184.

18. Bouhassira D, Chassany O, Gaillat J, et al. Patient perspective on herpes zoster and its complications: An observational prospective study in patients aged over 50 years in general practice. Pain 2012;153:342-9.

19. Drolet M, Brisson M, Schmader KE, et al. The impact of herpes zoster and postherpetic neuralgia on health-related quality of life: A prospective study. CMAJ 2010;182:1731-6.

20. Pickering G, Leplège $A$. Herpes zoster pain, postherpetic neuralgia, and quality of life in the elderly. Pain Pract 2011;11:397-402.

21. Li Q, Chen N, Yang J, et al. Antiviral treatment for preventing postherpetic neuralgia. Cochrane Database Syst Rev 2009;(2):CD006866

22. Lapolla W, Digiorgio C, Haitz K, et al. Incidence of postherpetic neuralgia after combination treatment with gabapentin and valacyclovir in patients with acute herpes zoster: Open-label study. Arch Dermatol 2011;147:901-7.

23. Fett N. Gabapentin not shown to prevent postherpetic neuralgia. Arch Dermatol 2012;148:400-1.

24. Yarnitsky D. Conditioned pain modulation (the diffuse noxious inhibitory control-like effect): Its relevance for acute and chronic pain states. Curr Opin Anaesthesiol 2010;23:611-5.

25. LeBars D, Villanueva L, Bouhassira D, Willer JC. Diffuse noxious inhibitory controls (DNIC) in animals and in man. Patol Fiziol Eksp Ter 1992:55-65.

26. Villanueva L, LeBars D. The activation of bulbo-spinal controls by peripheral nociceptive inputs: Diffuse noxious inhibitory controls Biol Res 1995;28:113-25.

27. Goffaux P, Redmond WJ, Rainville P, Marchand S. Descending analgesia - when the spine echoes what the brain expects. Pain 2007;130:137-43.
28. Oono Y, Fujii K, Motohashi K, Umino M. Diffuse noxious inhibitory controls triggered by heterotopic $\mathrm{CO}_{2}$ laser conditioning stimulation decreased the SEP amplitudes induced by electrical tooth stimulation with different intensity at an equally inhibitory rate. Pain 2008;136:356-65.

29. Moont R, Pud D, Sprecher E, Sharvit G, Yarnitsky D. "Pain inhibits pain" mechanisms: Is pain modulation simply due to distraction? Pain 2010;150:113-20.

30. Sprenger C, Bingel U, Büchel C. Treating pain with pain: Supraspinal mechanisms of endogenous analgesia elicited by heterotopic noxious conditioning stimulation. Pain 2011;152:428-39.

31. Rhudy JL, Williams AE, McCabe KM, Nguyen MA, Rambo P. Affective modulation of nociception at spinal and supraspinal levels. Psychophysiology 2005;42:579-87.

32. Garcia-Larrea L. Objective pain diagnostics: Clinical neurophysiology. Neurophysiol Clin 2012;42:187-97.

33. Granovsky Y, Matre D, Sokolik A, Lorenz J, Casey KL. Thermoreceptive innervation of human glabrous and hairy skin: A contact heat evoked potential analysis. Pain 2005;115:238-47.

34. Pud D, Granovsky Y, Yarnitsky D. The methodology of experimentally induced diffuse noxious inhibitory control (DNIC)like effect in humans. Pain 2009;144:16-9.

35. Pickering G, Estève V, Loriot MA, Eschalier A, Dubray C. Acetaminophen reinforces descending inhibitory pain pathways. Clin Pharmacol Ther 2008;84:47-51.

36. Van Wijk G, Veldhuijzen DS. Perspective on diffuse noxious inhibitory controls as a model of endogenous pain modulation in clinical pain syndromes. J Pain 2010;11:408-19.

37. Perrotta A, Serpino C, Cormio C, et al. Abnormal spinal cord pain processing in Huntington's disease. The role of the diffuse noxious inhibitory control. Clin Neurophysiol 2012;123:1624-30.

38. De Broucker T, Cesaro P, Willer JC, Le Bars D. Diffuse noxious inhibitory controls in man. Involvement of the spinoreticular tract. Brain 1990;113:1223-34.

39. Granovsky Y, Schlesinger I, Fadel S, Erikh I, Sprecher E, Yarnitsky D. Asymmetric pain processing in Parkinson's disease. Eur J Neurol 2013;20:1375-82.

40. Leffler AS, Kosek E, Lerndal T, Nordmark B, Hansson P. Somatosensory perception and function of diffuse noxious inhibitory controls (DNIC) in patients suffering from rheumatoid arthritis. Eur J Pain 2002;6:161-76.

41. Mylius V, Engau I, Teepker M, et al. Pain sensitivity and descending inhibition of pain in Parkinson's disease. J Neurol Neurosurg Psychiatry 2009;80:24-8.

42. Yarnitsky D, Crispel Y, Eisenberg E, et al. Prediction of chronic post-operative pain: Pre-operative DNIC testing identifies patients at risk. Pain 2008;138:22-8.

43. Wilder-Smith OH, Schreyer T, Scheffer GJ, Arendt-Nielsen L. Patients with chronic pain after abdominal surgery show less preoperative endogenous pain inhibition and more postoperative hyperalgesia: A pilot study. J Pain Palliat Care Pharmacother 2010;24:119-28.

44 Kosek E, Ordeberg G. Lack of pressure pain modulation by heterotopic noxious conditioning stimulation in patients with painful osteoarthritis before, but not following, surgical pain relief. Pain 2000;88:69-78.

45. Arendt-Nielsen L, Sluka KA, Nie HL. Experimental muscle pain impairs descending inhibition. Pain 2008;140:465-71.

46. Bouhassira D, Danziger N, Attal N, Guirimand F. Comparison of the pain suppressive effects of clinical and experimental painful conditioning stimuli. Brain 2003;126:1068-78.

47. Peters ML, Schmidt AJ, Van den Hout MA, Koopmans R, Sluijter ME. Chronic back pain, acute postoperative pain and the activation of diffuse noxious inhibitory controls (DNIC). Pain 1992;50:177-87.

48. Boureau F, Luu M, Doubrère JF. Study of experimental pain measures and nociceptive reflex in chronic pain patients and normal subjects. Pain 1991;44:131-8.

49. Nir RR, Yarnitsky D, Honigman L, Granot M. Cognitive manipulation targeted at decreasing the conditioning pain perception reduces the efficacy of conditioned pain modulation. Pain 2012;153:170-6. 


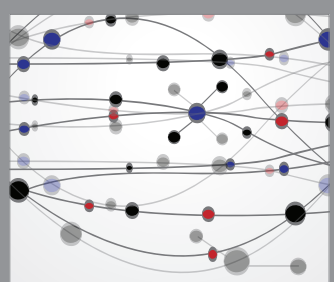

The Scientific World Journal
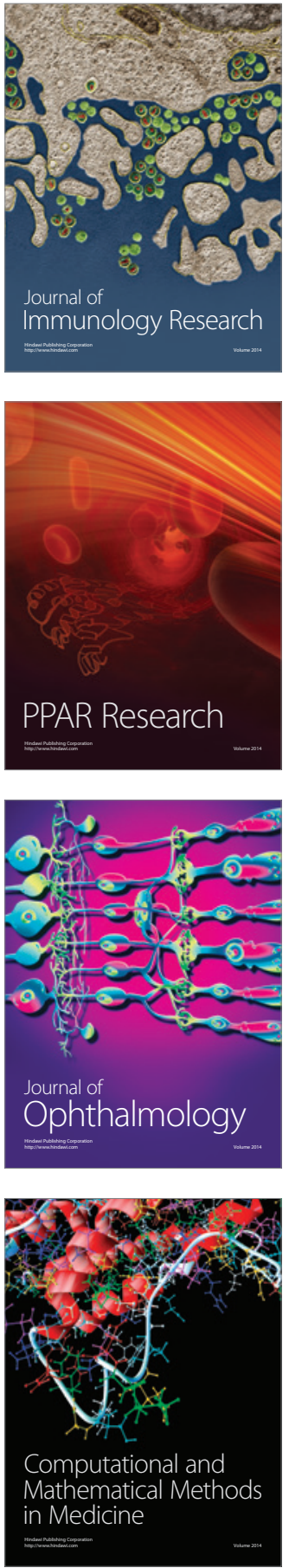

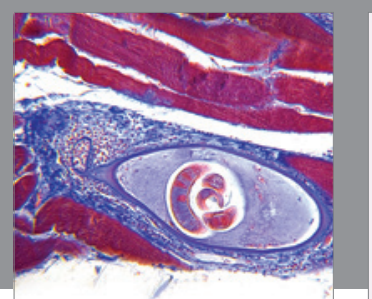

Gastroenterology Research and Practice

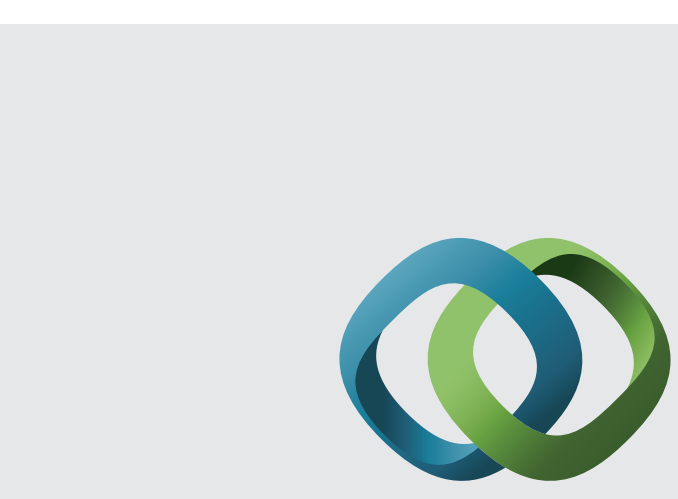

\section{Hindawi}

Submit your manuscripts at

http://www.hindawi.com
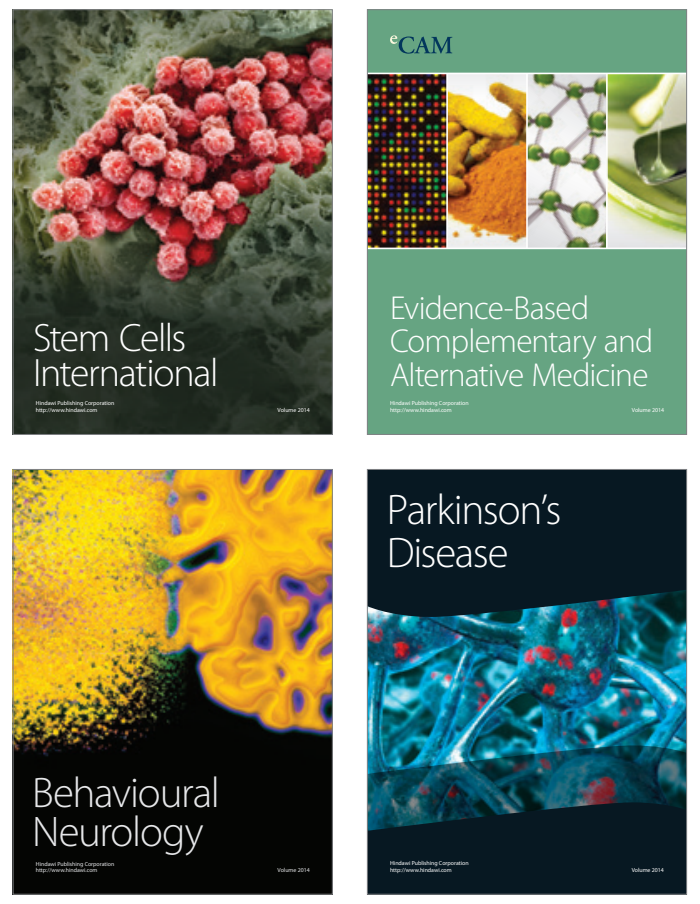
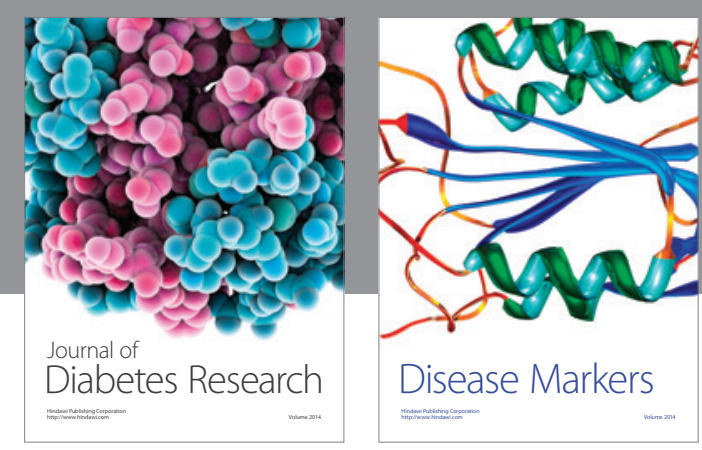

Disease Markers
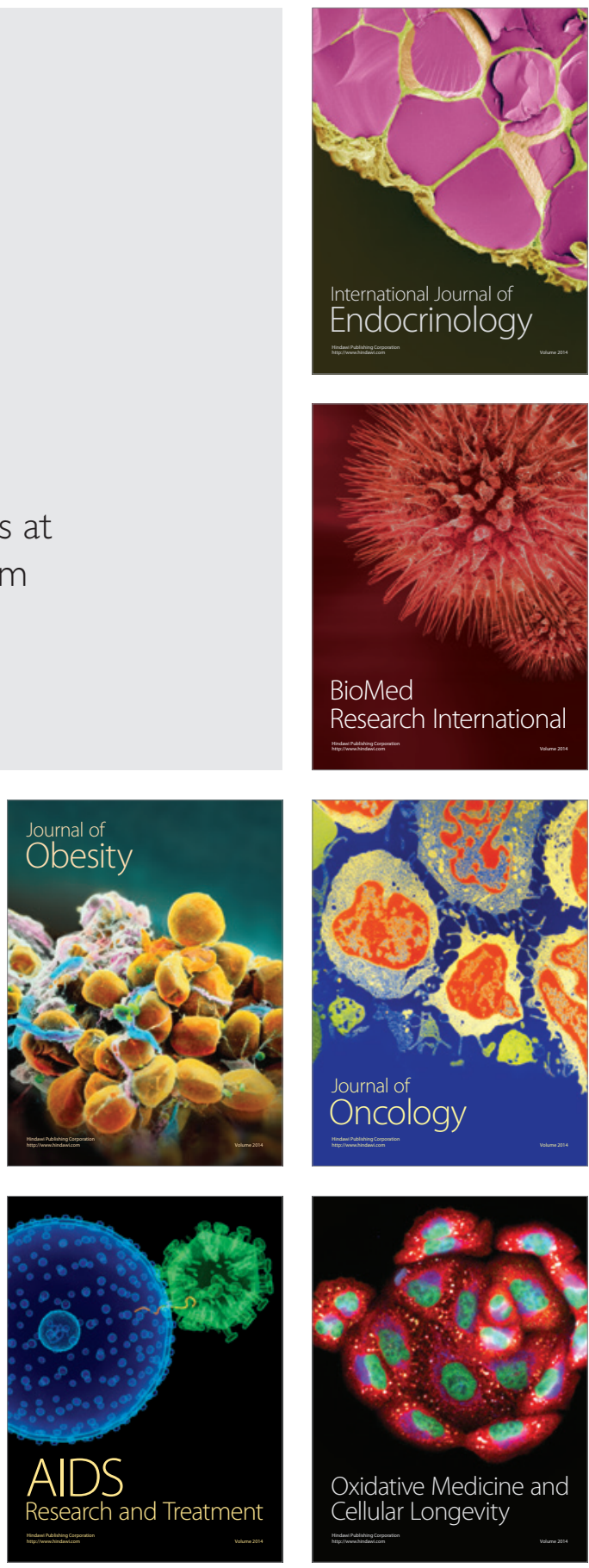